\title{
Frequency of physical activity and stress levels among Brazilian adults during social distancing due to the coronavirus (COVID-19): cross-sectional study
}

\author{
Edina Maria de Camargo', Thiago Silva Piola", Letícia Pechnicki dos Santos"'I, Edilson Fernando de Borba", \\ Wagner de Campos" ${ }^{v}$, Sergio Gregorio da Silva ${ }^{\mathrm{vl}}$
}

Universidade Federal do Paraná (UFPR), Curitiba (PR), Brazil

IPhD. Physical Education Teacher, Postgraduate Program on Physical Education, Universidade Federal do Paraná (UFPR), Curitiba (PR), Brazil. (D) https://orcid.org/0000-0003-2127-2606

"PhD. Physical Education Teacher, Postgraduate Program on Physical Education, Universidade Federal do Paraná (UFPR), Curitiba (PR), Brazil. (D) https://orcid.org/0000-0002-6081-0510

"'MSc. Physical Education Teacher, Postgraduate Program on Physical Education, Universidade Tecnológica Federal do Paraná (UTFPR), Curitiba (PR), Brazil.

(D) https://orcid.org/0000-0002-4443-5191

IVSC. Physical Education Teacher, Postgraduate Program on Physical Education, Universidade Federal do Paraná (UFPR), Curitiba (PR), Brazil. (D) https://orcid.org/0000-0002-9399-1098

vphD. Physical Education Teacher, Postgraduate Program on Physical Education, Universidade Federal do Paraná (UFPR), Curitiba (PR), Brazil.

(D) https://orcid.org/0000-0003-3979-1017

v'PhD. Physical Education Teacher, Postgraduate Program on Physical Education, Universidade Federal do Paraná (UFPR), Curitiba (PR), Brazil. (D) https://orcid.org/0000-0002-0714-1338

KEY WORDS (MeSH terms):

Epidemiology.

Pandemics.

Exercise.

AUTHORS' KEY WORDS:

SARS.

Stress.

Physical activity.

\begin{abstract}
BACKGROUND: The COVID-19 pandemic may be having many psychological impacts on people, at both an individual and a community level.

OBJECTIVE: To ascertain the relationship between the weekly frequency of physical activity and levels of stress among Brazilian adults during social distancing due to the coronavirus (COVID-19), and the interaction of sex in this association.

DESIGN AND SETTING: Cross-sectional study with a descriptive approach conducted at a public university in Curitiba (PR), Brazil.

METHODS: 2,000 Brazilian adults (average age 36.4 years; 59.6\% women) were recruited according to convenience through digital media. They filled out a questionnaire in electronic format that asked for sociodemographic information, health data, food consumption data, weekly frequency of physical activity and stress levels on the 10-item Kessler psychological distress scale. Descriptive statistics and regression analyses were used to evaluate the data.

RESULTS: Associations were observed for the following correlations: male sex * no physical activity (odds ratio (OR): 4.35; 95\% confidence interval (Cl): 1.14-16.67); female sex * physical activity 4 or 5 times a week (OR: 7.86; 95\% Cl: 2.28-27.05); female sex* physical activity 3 times a week (OR: 7.32; 95\% Cl: 2.09-25.58); female sex * physical activity 1 or 2 times a week (OR: 14.57; 95\% Cl: 4.28-49.57); and female sex * no physical activity (OR: 24.17; 95\% Cl: 7.21-80.97).

CONCLUSION: The lower the weekly frequency of physical activity during the period of social distancing was, the greater the chances of having stress levels were, especially for women.
\end{abstract}

\section{INTRODUCTION}

The COVID-19 pandemic may be having many psychological impacts on people, at both an individual and a community level. ${ }^{1,2}$ The few studies published to date have shown that in the initial phase of the COVID-19 outbreak, more than half of the respondents rated its psychological impact as moderate to severe, and about a third reported having moderate to severe anxiety. ${ }^{3}$

In relation to the current pandemic scenario, both the Brazilian Ministry of Health and the World Health Organization recommend social distancing. However, it is known that long periods in isolation can increase behaviors that lead to physical inactivity, thereby contributing to the development of anxiety and depression. ${ }^{4-6}$

Thus, maintaining some frequency of physical activity in the home (aerobic activities, stretching and muscle and bone-strengthening exercises), during this period of social distancing, could help control stress levels, such as anxiety and depression. ${ }^{7}$ It has been suggested that higher levels of physical activity are associated with decreased risk of future anxiety disorders and depression. ${ }^{8,9}$ These results have been confirmed through recent meta-analyses, in which regular physical activity was seen to be a protective factor against depression. ${ }^{9,10}$

Based on the numerous health benefits that physical activity may provide, ${ }^{11-13}$ and considering the importance of maintaining physical activity during the COVID-19 pandemic, especially for controlling stress levels, such as anxiety and depression, ${ }^{7-10}$ it is necessary to expand knowledge about the role of the weekly frequency of physical activity. 


\section{OBJECTIVE}

The objective of the study was to ascertain the relationship between the weekly frequency of physical activity and the level of stress among Brazilian adults during social distancing due to the coronavirus (COVID-19), and the interaction of sex with this association.

\section{METHODS}

\section{Ethical considerations}

The present study followed the rules for research involving human beings of the Brazilian National Health Council. It was approved by the local university research ethics committee (CAAE: 30750220.1.0000.0102; date: June 9, 2020).

\section{Procedures}

This was a cross-sectional, epidemiological and correlational study carried out using a non-probabilistic sample of Brazilian adults who were selected according to convenience. The sample was invited (from April to May 2020) to participate in the survey through dissemination in digital media (WhatsApp, Telegram, Facebook, Twitter and e-mails). Through these media, those interested in participating in the study had access to a questionnaire (available through Google Forms), named: "Questionnaire on habitual physical activity practices, eating habits and psychological factors during social distancing due to the new coronavirus (COVID-19)".

A total of 2,347 adults were evaluated. Respondents who were under 18 years old $(n=38)$ and duplicate responses $(n=74)$ were excluded. Individuals who answered the questionnaires incorrectly were treated as sample loss $(\mathrm{n}=235)$. Thus, the final sample included consisted of 2,000 Brazilian adults.

To verify the statistical power of the sample, an a posteriori sample calculation was performed considering a $95 \%$ confidence level $(\alpha=0.05)$, an $80 \%$ power $(\beta=20)$ and a prevalence of physical activity of three times per week during social distancing of $21.1 \%$ (distribution of the sample itself). With these parameters, the sample of 2,000 subjects made it possible to identify prevalence ratios above 1.28 as a risk and below 0.75 as protection. These calculations were performed on the calculator $G^{*}$ Power version 3.1.9.4 (G*Power, Dusseldorf, Germany).

\section{Independent variable - physical activity (PA)}

To assess physical activity at home (aerobic activities, stretching and muscle and bone-strengthening exercises) during social distancing, the following question was asked: "How often have you been practicing physical activity during social distancing?" The response options were: No exercise, 1 or 2 times a week, 3 times a week, 4 or 5 times a week or 6 or 7 times a week. The respondents were also asked at what time they performed this physical activity on a daily basis. However, the frequency of physical activity during the week was considered for analysis.

\section{Dependent variable - stress level}

The respondents' stress level was assessed using the K10 instrument. ${ }^{14}$ This instrument consists of 10 questions and assesses anxiety and depression over the last 30 days. The first nine questions all begin "During the past 30 days, how often did you feel..." and are completed with the following: "... exhausted for no good reason?”; “... nervous?”; “... so nervous that nothing could calm you down?”; “... hopeless?”; “... restless or agitated?”; “... so restless that you couldn't stand still?”; “... depressed?”; “... so depressed that nothing could cheer you up?"; and “... worthless?”. Finally, the last question is "During the past 30 days, how often did you feel that everything was an effort?".

The answer options were obtained using a Likert scale (never, a little, part of the time, most of the time and all the time). These answers to the 10 questions were summed to generate a final score, which could range from 10 to 50 . These scores were used to estimate the level of anxiety or depression. Thus, the participants were classified as presenting low stress (scores of 10 to 15), moderate stress (16 to 21 ), high stress (22 to 29 ) or very high stress (30 to $50)$. For respondents with a total score greater than 22 , there is a greater risk of having a mental disorder. ${ }^{15}$

\section{Sociodemographic and health factors}

Sex was self-reported ("male" or "female"). Likewise, age was informed by the participants and was then grouped as: 18-29 years, 30-39 years, $40-49$ years, $50-59$ years or over 60 years. The body mass index (BMI) was calculated from self-reported weight and height in the questionnaire. It was obtained by dividing weight (kilograms) by height (meters) squared and was classified as specified by the World Health Organization (WHO): "underweight" (< $\left.18.5 \mathrm{~kg} / \mathrm{m}^{2}\right)$; "normal weight" (18.5 to $\left.24.9 \mathrm{~kg} / \mathrm{m}^{2}\right)$; "overweight" (25 to $\left.29.9 \mathrm{~kg} / \mathrm{m}^{2}\right)$; or "obesity" $\left(\geq 30 \mathrm{~kg} / \mathrm{m}^{2}\right) .{ }^{16}$ The respondents were also asked whether they had increased their food consumption during social distancing, with the following response options: no, sometimes or yes.

\section{Data analysis and statistical procedures}

The data were described in terms of simple and relative frequencies, according to the stress level of the subjects. The chi-square test was used to compare the frequencies of factors at different levels of stress.

Possible associations between different levels of stress and sex, frequency of physical activities during social distancing, age groups, body mass index and increased food intake during social distancing were investigated through crude multinomial logistic regression (the proportionality of odds had previously been verified), with their respective $95 \%$ confidence intervals. 
Subsequently, the interaction of sex was tested in the relationship between weekly frequency of physical activities and stress during social distancing (for example: sex * frequency of physical activity). For this, the interaction term was introduced into the models for multinomial logistic regression analysis (with 95\% confidence intervals).

All the analyses were performed using the SPSS software, version 24.0 (Chicago, IL, United States), with a significance level set at $\mathrm{P}<0.05$.

\section{RESULTS}

The final sample was 2,000 adults (59.6\% women), with predominance of the age group between 30 and 39 years (34.2\%). Approximately half of the sample (49.3\%) was classified as having normal weight, $42.2 \%$ reported not having increased their food consumption and $23.8 \%$ were practicing physical activities 4 to 5 times a week. Regarding stress, the low level was seen most frequently in the sample (35.9\%) (Table 1). Higher levels of stress were associated with the following: females, in comparison with males (OR: 5.30; 95\% CI: 3.59-7.82); low frequency of weekly physical activity, in comparison with high frequency of weekly physical activity ( 4 or 5 times: OR: 2.58 ; 95\% CI: 1.23 5.41; 3 times: OR: 3.01; 95\% CI: 1.44-6.28; once or twice: OR:
4.71; 95\% CI: 2.27-9.75; and not done: OR: 9.73; 95\% CI: 4.80 19.69); and the age groups of 30 to 39 years (OR: 5.99; 95\% CI: 1.41-25.32) and 18 to 29 years (OR: 17.61; 95\% CI: 4.19-73.94), in comparison with the age group of 60 years and over. Higher levels of stress were inversely associated with the following: overweight, in comparison to obesity (OR: 0.56 ; 95\% CI: 0.35-0.90); and increased food intake: sometimes (OR: 0.49; 95\% CI: 0.32 0.73 ) and none (OR: 0.24 ; 95\% CI: 0.16-0.35), in comparison with increased food intake (Table 2).

When sex was inserted as an interaction term in the association between the weekly frequency of physical activity and the stress level, significant values were presented for the following: male sex * no physical activity (OR: 4.35; 95\% CI: 1.14-16.67); female sex * physical activity 4 or 5 times a week (OR: 7.86; 95\% CI; 2.28-27.05); female sex * physical activity 3 times a week (OR: 7.32; 95\% CI \%: 2.09-25.58); female sex ${ }^{\star}$ physical activity 1 or 2 times a week (OR: 14.57; 95\% CI: 4.28-49.57); and female sex * no physical activity (OR: 24.17; 95\% CI: 7.21-80.97) (Table 3).

\section{DISCUSSION}

Regarding the initial hypothesis of this study, the analyses confirmed the premise that the lower the weekly frequency of physical activity during the period of social distancing was, the greater

Table 1. Characteristics of this sample of Brazilians according to their stress levels during the social distancing due to COVID-19 ( $\mathrm{n}=2,000)$

\begin{tabular}{|c|c|c|c|c|c|c|c|c|c|}
\hline & \multicolumn{8}{|c|}{ Stress level } & \multirow{3}{*}{$\mathbf{P}$} \\
\hline & \multicolumn{2}{|c|}{ Low } & \multicolumn{2}{|c|}{ Moderate } & \multicolumn{2}{|c|}{ High } & \multicolumn{2}{|c|}{ Very high } & \\
\hline & $n$ & $\%$ & $n$ & $\%$ & $n$ & $\%$ & n & $\%$ & \\
\hline \multicolumn{10}{|l|}{ Sex } \\
\hline Male & $335^{\mathrm{a}}$ & 16.8 & $400^{b}$ & 20.0 & $290^{c}$ & 14.5 & $167^{d}$ & 8.3 & $<0.001$ \\
\hline Female & $383^{a}$ & 19.1 & $275^{b}$ & 13.8 & $114^{c}$ & 5.7 & $36^{d}$ & 1.8 & \\
\hline \multicolumn{10}{|c|}{ Weekly frequency of physical activities during social distancing } \\
\hline 6 or 7 times & $136^{\mathrm{a}}$ & 6.8 & $72 b$ & 3.6 & $27^{b}$ & 1.4 & $10^{\mathrm{b}}$ & 0.5 & $<0.001$ \\
\hline 4 or 5 times & $179^{a . b}$ & 8.9 & $182^{\mathrm{b}}$ & 9.1 & $80^{\mathrm{a}}$ & 4.0 & $34^{\mathrm{a}}$ & 1.7 & \\
\hline 3 times & 167 & 8.3 & 135 & 6.8 & 82 & 4.1 & 37 & 1.8 & \\
\hline Once or twice & $127^{a}$ & 6.3 & $151^{a \cdot b}$ & 7.5 & $105^{b}$ & 5.3 & $44^{a, b}$ & 2.2 & \\
\hline Not practiced & $109^{a}$ & 5.5 & $135^{\mathrm{a}}$ & 6.8 & $110^{b}$ & 5.5 & $78^{c}$ & 3.9 & \\
\hline \multicolumn{10}{|l|}{ Age group } \\
\hline 60 years and over & $51^{a}$ & 2.5 & $23^{b}$ & 1.1 & $7^{b}$ & 0.4 & $2^{b}$ & 0.1 & $<0.001$ \\
\hline 50 to 59 years & $92^{\mathrm{a}}$ & 4.6 & $63^{a \cdot b}$ & 3.1 & $23^{b}$ & 1.1 & $9^{b}$ & 0.4 & \\
\hline 40 to 49 years & $172^{\mathrm{a}}$ & 8.6 & $137^{a . b}$ & 6.9 & $71^{a . b}$ & 3.5 & $28^{b}$ & 1.4 & \\
\hline 30 to 39 years & 251 & 12.6 & 230 & 11.5 & 144 & 7.2 & 59 & 2.9 & \\
\hline 18 to 29 years & $152^{\mathrm{a}}$ & 7.6 & $222^{b}$ & 11.1 & $159^{b}$ & 8.0 & $105^{c}$ & 5.3 & \\
\hline \multicolumn{10}{|l|}{ Body mass index } \\
\hline Obese & 87 & 4.3 & 86 & 4.3 & 63 & 3.1 & 36 & 1.8 & 0.713 \\
\hline Overweight & 266 & 13.3 & 254 & 12.7 & 127 & 6.3 & 62 & 3.1 & \\
\hline Normal & 356 & 17.8 & 325 & 16.3 & 206 & 10.3 & 98 & 4.9 & \\
\hline Underweight & 9 & 0.4 & 10 & 0.5 & 8 & 0.4 & 7 & 0.4 & \\
\hline \multicolumn{10}{|c|}{ Increased food intake during social distancing } \\
\hline Yes & $129^{a}$ & 6.5 & $189^{b}$ & 9.4 & $147^{c}$ & 7.3 & $82^{c}$ & 4.1 & $<0.001$ \\
\hline Sometimes & 192 & 9.6 & 221 & 11.1 & 137 & 6.9 & 60 & 3.0 & \\
\hline No & $397^{a}$ & 19.9 & $265^{b}$ & 13.3 & $120^{c}$ & 6.0 & $61^{\text {b.c }}$ & 3.0 & \\
\hline
\end{tabular}

a,b,c,differ significantly. 
the chances were that the subjects would present high levels of stress, even after considering adjustments for overweight and obesity, ${ }^{17}$ age and food consumption, ${ }^{18}$ which are factors that can also contribute to higher levels of stress. The Physical Activity Guidelines recommend that all adults, even those with chronic medical conditions, should engage in at least 150 minutes (recommended minimum) to 300 minutes a week of moderateintensity exercise, if they are able to. ${ }^{19}$
These minimum recommendations are equivalent to something like 30 minutes a day of physical activity, 4 to 5 days a week, in order to obtain health benefits. ${ }^{19}$ The present study showed that adults (regardless of sex) who reported doing physical activity at this frequency in a regular week would be twice as likely to experience moderate stress and three times as likely to experience high and very high stress, compared with those who did higher frequencies of physical activities (6 to 7 times a week). These stress

Table 2. Factors associated with stress levels among this sample of Brazilians during the social distancing due to COVID-19 ( $\mathrm{n}=2,000)$

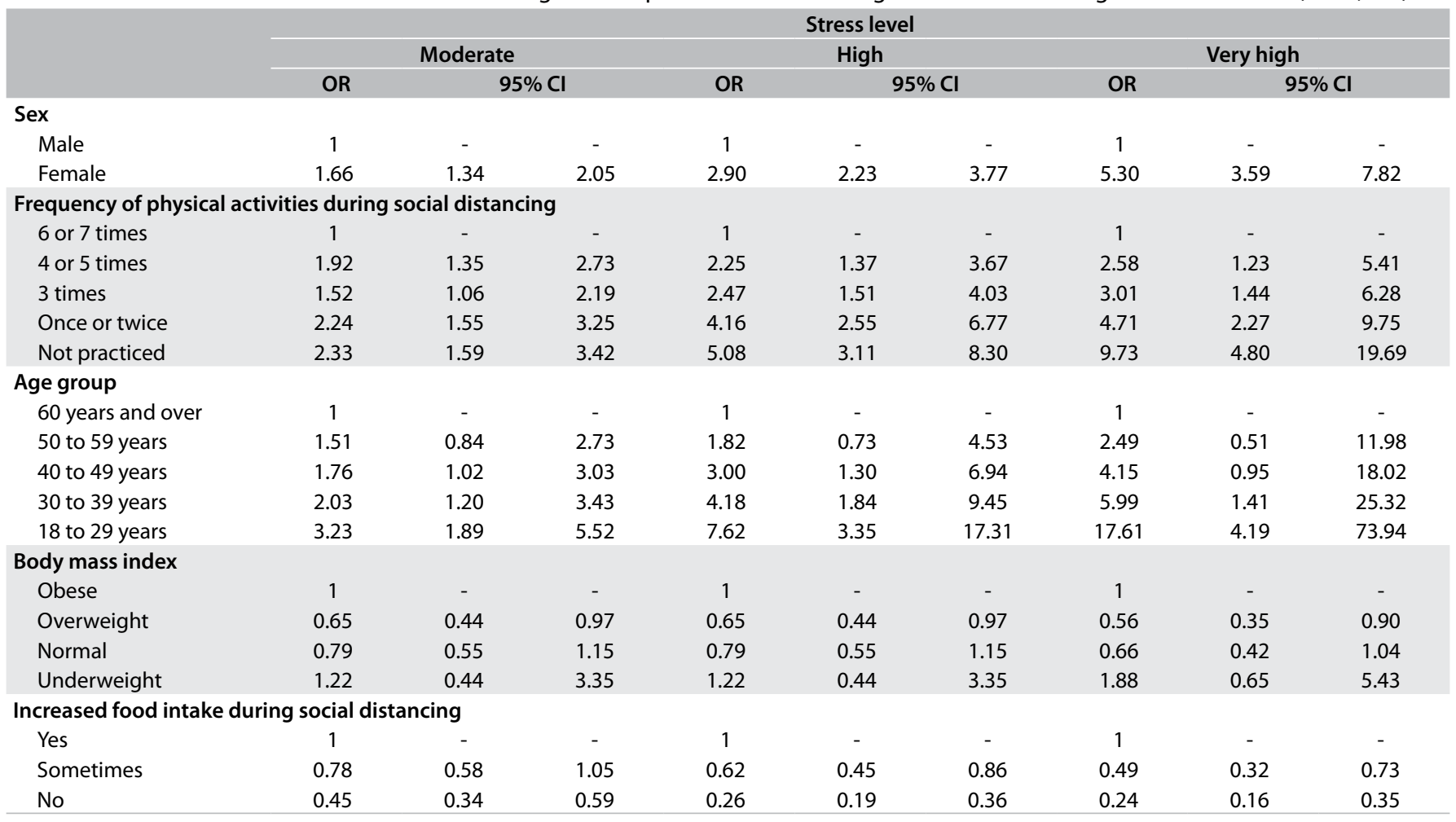

$\mathrm{OR}=$ odds ratio; $\mathrm{Cl}=$ confidence interval; $\mathrm{P}<0.05$.

Table 3. Interaction of sex in the association between weekly frequency of physical activity and stress levels among this sample of Brazilians during the social distancing due to COVID-19 $(n=2,000)$

\begin{tabular}{|c|c|c|c|c|c|c|c|c|c|}
\hline & \multicolumn{9}{|c|}{ Stress level } \\
\hline & \multicolumn{3}{|c|}{ Moderate } & \multicolumn{3}{|c|}{ High } & \multicolumn{3}{|c|}{ Very high } \\
\hline & OR & \multicolumn{2}{|c|}{$95 \% \mathrm{Cl}$} & OR & \multicolumn{2}{|c|}{$95 \% \mathrm{Cl}$} & OR & \multicolumn{2}{|c|}{$95 \% \mathrm{Cl}$} \\
\hline \multicolumn{10}{|c|}{ Weekly frequency of physical activity * Male } \\
\hline 6 or 7 times & 1 & - & - & 1 & - & - & 1 & - & - \\
\hline 4 or 5 times & 2.02 & 1.18 & 3.44 & 1.86 & 0.82 & 4.21 & 1.24 & 0.30 & 5.14 \\
\hline 3 times & 1.35 & 0.77 & 2.35 & 1.92 & 0.84 & 4.34 & 2.98 & 0.82 & 10.80 \\
\hline Once or twice & 2.01 & 1.13 & 3.57 & 2.76 & 1.20 & 6.34 & 0.95 & 0.18 & 4.90 \\
\hline Not practiced & 2.22 & 1.21 & 4.06 & 3.62 & 1.55 & 8.47 & 4.35 & 1.14 & 16.67 \\
\hline \multicolumn{10}{|c|}{ Weekly frequency of physical activity * Female } \\
\hline 6 or 7 times & 1.48 & 0.82 & 2.65 & 1.77 & 0.74 & 4.23 & 2.07 & 0.51 & 8.35 \\
\hline 4 or 5 times & 2.93 & 1.70 & 5.04 & 4.95 & 2.27 & 10.82 & 7.86 & 2.28 & 27.05 \\
\hline 3 times & 2.76 & 1.58 & 4.81 & 5.83 & 2.66 & 12.78 & 7.32 & 2.09 & 25.58 \\
\hline Once or twice & 3.71 & 2.13 & 6.46 & 9.36 & 4.31 & 20.30 & 14.57 & 4.28 & 49.57 \\
\hline Not practiced & 3.51 & 2.01 & 6.13 & 10.07 & 4.65 & 21.80 & 24.17 & 7.21 & 80.97 \\
\hline
\end{tabular}

$\mathrm{OR}=$ odds ratio; $\mathrm{Cl}=$ confidence interval; *Interaction = multiplication of the possible moderating variable (sex) in the relationship between weekly frequency and stress during distancing; $P<0.05$. 
values (moderate, high and very high) increased as the frequency of physical activity in the week decreased. This explains not only the importance of complying with the minimum recommendations, but also the protective role that regular physical activity can play regarding health, when it is done at frequencies higher than the recommended minimum. ${ }^{19}$

Our results highlighted that individuals who had ceased to do physical activity showed significantly higher levels of stress. These findings were concordant with the results from previous studies in which the benefits of physical activity were investigated. Physical activity has a major role in mental health and cognitive function, because exercise has positive effects with regard to preventing and alleviating depression and anxiety. ${ }^{10,20,21}$ Our findings corroborate those of other studies that have investigated mental health and physical activity during COVID-19.22,23

For men, this association was not observed for high and very high stress, which would be in line with the recommendations, because with frequencies of physical activity of four to five times a week, the psychological responses seem to improve considerably. ${ }^{10,20-23}$ In contrast, if women were to follow the recommendations, this would not be enough to decrease the chances of moderate, high and very high stress. For women, practicing physical activities six or seven times a week did not show any association with different levels of stress. The fact is that, according to the literature, women are more prone to higher levels of stress. ${ }^{10,20-23}$ The results from the present survey indicate that, despite the lack of significant values, higher frequency of physical activities during the social distancing period would indicate a lower level of stress.

Despite the recommendations that home confinement (lockdown) should not prevent people from being physically active, ${ }^{24}$ the results from our study showed that a portion of the sample investigated did not do any physical activity during the COVID-19 home confinement period. It is likely elderly individuals have difficulty in exercising alone at home and have less access to remote physical activity areas. This may explain the reduction in physical activity among elderly people during this period. ${ }^{23,24}$ Further studies are needed to understand why women experience higher levels of stress than those of men.

In short, the present study contributes to enabling better understanding of the literature on the importance of maintaining a regular frequency of physical activity. ${ }^{24}$ For individuals who reduce their weekly frequency of physical activity, there is an extremely high chance of having high levels of stress, related to anxiety and depression. ${ }^{14}$

Some limitations of our study need to be considered in order to better understand the results. Reverse causality, which is a common feature in studies with a cross-sectional design, does not allow investigation of a cause-and-effect relationship or determination of the direction of the relationships. Nonetheless, this design has been used in several studies like ours. The use of reported measurements depends on the accuracy and recall power of the respondent's responses. However, because our study was large, and because of the special conditions of distancing currently imposed in the vast majority of countries around the world, the use of questionnaires may be the best alternative. It was not possible to assess the type of physical activity (aerobic activities, stretching or muscle and bone-strengthening exercises), since the questionnaire spoke of physical activity in general. Future studies can ascertain the action of the type of physical activity performed.

\section{CONCLUSION}

The lower the weekly frequency of physical activity during the period of social distancing was, the greater the chances were that the subjects would present high levels of stress. The interaction term (sex) showed that, especially for women, the reduction in training frequencies during the week contributed to increases in moderate, high and very high levels of stress, 14-fold for women who maintained physical activity only 1 or 2 times a week and 24-fold for those who did not do any weekly physical activity. In summary, our study presents relevant findings about the importance of maintaining the frequency of physical activity, either at home or away from home.

\section{REFERENCES}

1. Qiu J, Shen B, Zhao M, et al. A nationwide survey of psychological distress among Chinese people in the COVID-19 epidemic: Implications and policy recommendations. Gen Psychiatry. 2020;33(2):19-21. PMID: 32215365; https://doi.org/10.1136/gpsych-2020-100213.

2. Van Bortel T, Basnayake A, Wurie F, et al. Psychosocial effects of an Ebola outbreak at individual, community and international levels. Bull World Health Organ. 2016;94(3):210-4. PMID: 26966332; https://doi. org/10.2471/blt.15.158543.

3. Wang C, Pan R, Wan X, et al. Immediate psychological responses and associated factors during the initial stage of the 2019 coronavirus disease (COVID-19) epidemic among the general population in China. Int J Environ Res Public Health. 2020;17(5):1729. PMID: 32155789; https:// doi.org/10.3390/ijerph17051729.

4. Ministério da Saúde. Coronavírus: O Que Você Precisa Saber. 2020 Available from: https://coronavirus.saude.gov.br/sobre-a-doenca\#comose-proteger. Accessed in 2020 (Nov 20).

5. World Health Organization. Coronavirus disease (COVID-19) advice for the public. 2020. Available from: https://www.who.int/emergencies/ diseases/novel-coronavirus-2019/advice-for-public. Accessed in 2020 (Nov 20).

6. Chen P, Mao L, Nassis GP, et al. Coronavirus disease (COVID-19): The need to maintain regular physical activity while taking precautions. J Sport Heal Sci. 2020;9(2):103-4. https://doi.org/10.1016/j.jshs.2020.02.001.

7. Jiménez-Pavón D, Carbonell-Baeza A, Lavie CJ. Physical exercise as therapy to fight against the mental and physical consequences of COVID-19 quarantine: 
Special focus in older people. Prog Cardiovasc Dis. 2020;63(3):386-8. PMID: 32220590; https://doi.org/10.1016/j.pcad.2020.03.009.

8. Schuch FB, Stubbs B, Meyer J, et al. Physical activity protects from incident anxiety: A meta-analysis of prospective cohort studies. Depress Anxiety. 2019;36(9):846-58. PMID: 31209958; http://dx.doi.org/10.1002/da.22915.

9. Schuch FB, Vancampfort D, Firth J, et al. Physical activity and incident depression: A meta-analysis of prospective cohort studies. Am J Psychiatry. 2018;175(7):631-48. PMID:29690792; https://doi.org/10.1176/ appi.ajp.2018.17111194.

10. Kandola A, Ashdown-Franks G, Hendrikse J, Sabiston CM, Stubbs B. Physical activity and depression: Towards understanding the antidepressant mechanisms of physical activity. Neurosci Biobehav Rev. 2019;107:52539. PMID: 31586447; https://doi.org/10.1016/j.neubiorev.2019.09.040.

11. Hadgraft NT, Winkler E, Climie RE, et al. Effects of sedentary behaviour interventions on biomarkers of cardiometabolic risk in adults: systematic review with meta-analyses. Br J Sports Med. 2020. Published online ahead of print. PMID: 32269058; https://doi.org/10.1136/bjsports-2019-101154.

12. Song Y, Ren F, Sun D, et al. Benefits of Exercise on Influenza or Pneumonia in Older Adults: A Systematic Review. Int J Environ Res Public Health. 2020;17(8):2655. PMID:32294922; https://doi.org/10.3390/ijerph17082655.

13. Ludyga S, Gerber M, Pühse U, Looser VN, Kamijo K. Systematic review and meta-analysis investigating moderators of long-term effects of exercise on cognition in healthy individuals. Nat Hum Behav. 2020;4(6):603-12. PMID: 32231280; https://doi.org/10.1038/s41562-020-0851-8.

14. Kessler RC, Andrew G, Colpe LJ, et al. Short screening scales to monitor population prevalences and trends in non-specific psychological distress. Psychol Med. 2002;32(6):959-76. PMID: 12214795; http://doi. org/10.1017/s0033291702006074.

15. Pereira A, Oliveira CA, Bártolo A, et al. Reliability and factor structure of the 10-item Kessler Psychological Distress Scale (K10) among Portuguese adults. Cienc Saude Colet. 2019;24(3):729-36. PMID: 30892495; https:// doi.org/10.1590/1413-81232018243.06322017.

16. World Health Organization. Obesity: preventing and managing the global epidemic. Geneva: World Health Organization; 2000. Available from: https://www.who.int/nutrition/publications/obesity/WHO_ TRS_894/en/. Accessed in 2020 (Nov 20).

17. Atlantis E, Ball K. Association between weight perception and psychological distress. J Int J Obes (Lond). 2008;32(4):715-21. PMID: 18408736; http://doi.org/10.1038/sj.ijo.0803762.

18. Penaforte FRO, Matta NC, Japur CC. Association between stress and eating behavior in college students. Demetra. 2016;1 1(1):225-37. http:// doi.org/10.12957/demetra.2016.18592.

19. World Health Organization. Global recommendations on physical activity for health. Geneva: World Health Organization; 2010. Available from: https://www.who.int/publications/i/item/9789241599979. Accessed in 2020 (Nov 20).
20. Mochcovitch MD, Deslandes AC, Freire RC, Garcia RF, Nardi AE. The effects of regular physical activity on anxiety symptoms in healthy older adults: a systematic review. Brazilian J Psychiatry. 2016;38(3):255-61. PMID: 27579597; http://doi.org/10.1590/1516-4446-2015-1893.

21. Netz Y, Wu MJ, Becker BJ, Tenenbaum G. Physical activity and psychological well-being in advanced age: a meta-analysis of intervention studies. Psychol Aging. 2005;20(2):272-84. PMID: 16029091; http://doi.org/10.1037/0882-7974.20.2.272.

22. Di Corrado D, Magnano P, Muzii B, et al. Effects of social distancing on psychological state and physical activity routines during the COVID-19 pandemic. Sport Sci Health. 2020:1-6. PMID: 32994822; https://doi. org/10.1007/s11332-020-00697-5.

23. Nyenhuis SM, Greiwe J, Zeiger JS, Nanda A, Cooke A. Exercise and Fitness in the Age of Social Distancing During the COVID-19 Pandemic. J Allergy Clin Immunol Pract. 2020;8(7):2152-5. PMID: 32360185; https:// doi.org/10.1016/j.jaip.2020.04.039.

24. American College of Sports Medicine. Staying Physically Active During the COVID-19 Pandemic. 2020. Available from: https://www.acsm.org/ read-research/newsroom/news-releases/news-detail/2020/03/16/ staying-physically-active-during-covid-19-pandemic. Accessed in 2020 (Nov 20).

Authors' contributions: Camargo EM, Piola TS, Santos LP, Borba EF, Campos W, da Silva SG: formal analysis (equal), investigation (equal), methodology (equal), writing-original draft (equal) and writing-review and editing (equal). All authors provided substantial contributions to the manuscript. They reviewed and approved the final version of the manuscript, and they guarantee the integrity of the article

\section{Sources of funding: None}

Conflict of interest: None

Date of first submission: November 23, 2020

Last received: December 18, 2020

Accepted: February 8, 2021

\section{Address for correspondence:}

Edina Maria de Camargo

Universidade Federal do Paraná

Novo Edifício do Departamento de Educação Física

Av. Coronel Francisco Heráclito dos Santos, 100

Caixa Postal 19061 — Campus Centro Politécnico

Curitiba (PR) - Brasil

CEP 81531-980

Tel. (+55 41) 3361-3072

E-mail: edinacamargo@gmail.com 